\title{
Quantification of human lithostathine by high performance liquid chromatography
}

\author{
J-P Bernard, M Barthet, B Gharib, R Michel, A Lilova, J Sahel, J-C Dagorn, M De Reggi
}

\begin{abstract}
Pancreatic stones of patients with chronic calcifying pancreatitis (CCP) are mostly made up of $\mathrm{CaCO} 3$ crystals. Formation and growth of such crystals is inhibited in vitro by lithostathine, a protein present in normal pancreatic juice. Decreased lithostathine activity was therefore suspected in patients with CCP, but comparison by immunoassay of lithostathine concentrations in the pancreatic juices of patients and controls led to conflicting results. This study shows that these discrepancies might have been caused in part by a remarkably high susceptibility of the protein to trypsin like cleavage, resulting in important structural changes and concomitant modifications of the epitopes. A novel lithostathine assay in juice was developed, based on separation of secretory proteins by high performance liquid chromatography. The chromatographic separation of lithostathine was based on hydrophobic interactions at $\mathrm{pH} 5 \cdot 0$ using a Phenyl-TSK column. This study showed with this assay that lithostathine concentrations $(\mu \mathrm{g} / \mathrm{mg}$ of total protein) were similar in CCP patients with alcoholic aetiology (mean (SD) $6.3(2 \cdot 7)$ ) and other aetiologies $(7.2(3.7))$, but one third of those estimated in patients without pancreatic disease $(16 \cdot 7(4 \cdot 3))$. Similar concentrations were found, however, in chronic alcoholic patients without CCP $(6 \cdot 6(3 \cdot 3))$ and in patients with CCP. It was concluded that decreased lithostathine concentration is associated with CCP, although such a decrease is not sufficient by itself for the disease to occur.

(Gut 1995; 36: 630-636)
\end{abstract}

Keywords: high performance liquid chromatography, pancreatitis, lithostathine.

The pancreatic stone protein, recently renamed lithostathine, ${ }^{1}$ is the major component of the organic matrix of pancreatic stones. It is also one of the most abundant nonenzymatic proteins secreted in pancreatic juice. ${ }^{23} \mathrm{Up}$ to four isoforms (lithostathine S2-5) have been described, with Mr ranging from 17 to $22 \mathrm{~K}$ the form with lower molecular weight being generally predominant in juice. All of them have the same polypeptide backbone and they differ only by their glycan chain, which is O-linked to Thr5. ${ }^{45}$ The removal of the $N$-terminal undecapeptide by trypsin cleavage of the Arg11-Ile 12 bond generates lithostathine $\mathrm{H} 2$, a 133 aminoacid polypeptide that precipitates at neutral $\mathrm{pH}$. That fragment is actually the $\mathrm{S} 1$ form previously described as pancreatic stone protein in pancreatic stones.

In vitro experiments have shown that lithostathine can inhibit $\mathrm{CaCO} 3$ nucleation and crystal growth. ${ }^{6}$ These findings led to the hypothesis that lithostathine participated in the control of stone formation in pancreatic ducts. In consequence patients with insufficient lithostathine concentration in juice were expected to be at risk for developing chronic calcifying pancreatitis (CCP). The finding that CCP patients had indeed reduced lithostathine mRNA concentration in pancreas supported that idea. ${ }^{7}$ Provansal-Cheylan et $a l^{8}$ also showed that lithostathine concentration measured by enzyme linked immunosorbent assay (ELISA) was reduced in patients with CCP, compared with controls. It was, however, disturbing that similar studies performed with a radioimmunoassay ${ }^{8}$ or a fluorescent immunoassay ${ }^{9}$ were used instead of an ELISA failed to show any difference, although the monoclonal antibody used for antigen captation was the same in the three techniques.

Such discrepancies cast a doubt on the pathophysiological significance of decreased lithostathine expression in the pancreas and should therefore be explained. This was the aim of this study, in which we looked at possible differences in the affinity of the antibodies for the various forms of lithostathine and investigated the possible interference with the assay of uncontrolled activation of trypsinogen leading to transformation by trypsin of lithostathine into its insoluble derivative. In addition, a reliable non-immunological procedure for evaluation of lithostathine concentration in juice was developed and used in patients presenting with CCP or other pancreatic diseases, in alcoholic patients, and in controls.

\section{Methods}

PANCREATIC JUICE

Samples of pancreatic juice were collected by endoscopic cannulation of the main pancreatic duct under secretin stimulation (1 U/kg body weight). Total protein concentration was estimated by optical density at $280 \mathrm{~nm}$. Only samples devoid of measurable chymotrypsin activity were used. Two ml samples were freeze dried until assay.

\section{PURIFICATION OF HUMAN LITHOSTATHINE}

Lithostathine was purified by means of an immunoaffinity column, using the commercial 
D4 monoclonal antibody (Immunotech, Marseille, France) linked to Affigel (Bio-Rad), as described previously, ${ }^{10}$ except for the washing step, which has been reinforced (total duration: 12 hours). Such an extensive washing of the column was necessary to remove all contaminating proteolytic agents to obtain a very stable protein. Cation exchange chromatography of the isoforms was performed by high performance liquid chromatography (HPLC) using a Mono S column (Pharmacia) equilibrated with MES buffer $\mathrm{pH}$ 6.5. Proteins were eluted by a linear $\mathrm{NaCl}$ gradient, from 0 to $0.25 \mathrm{M}$ in nine minutes (flow rate: 1 $\mathrm{ml} / \mathrm{min}$ ).

SUSCEPTIBILITY OF LITHOSTATHINE TO

HYDROLYSIS BY TRYPSIN

Purified lithostathine, $0.5 \mathrm{mg} / \mathrm{ml}$ in $50 \mathrm{mM}$ TRIS $\mathrm{pH} 8$, was incubated at $37^{\circ} \mathrm{C}$ with very low concentrations of trypsin (final concentration ranging from $5.6 \mathrm{nM}$ to $0.17 \mathrm{nM}$ ). The hydrolysis was monitored during 24 hours by sodium dodecyl sulphate polyacrylamide gel analysis ${ }^{11}$ and cation exchange chromatography.

\section{DETERMINATION OF THE RELATIVE ACTIVITY OF EACH LITHOSTATHINE ISOFORM IN THE ELISA TEST}

Quantification of each fraction obtained from chromatography of purified lithostathine on Mono S HPLC was performed using the ELISA method previously described. ${ }^{8}$ This method was a sandwich using Mabs D4 to lithostathine extracted from calculi as the solid phase bound first antibody and polyclonal rabbit antibody raised against lithostathine S2-5 for revelation.

Microplates (Flow Laboratories) were coated with $100 \mu \mathrm{l}$ of $2 \mu \mathrm{g} / \mathrm{ml} \mathrm{Mabs}$ and samples of lithostathine were incubated for one hour at room temperature. After three washing steps, each sample was incubated with $100 \mu$ l of polyclonal antibodies diluted $1 / 200$. Finally, after one hour a horseradish peroxydase conjugated goat antirabbit IgG $(\mathrm{H}+\mathrm{L})$ (Nordic) was added; peroxidase activity was monitored at $492 \mathrm{~nm}$ in a Titratek-Multiscan $\mathrm{R}$ (Flow Laboratories).

\section{HPLC METHOD FOR LITHOSTATHINE}

QUANTIFICATION IN PANCREATIC JUICE

HPLC separation of pancreatic juice proteins was performed on a Beckman Gold System. The buffers used were: (A) $0.1 \mathrm{M}$ sodium citrate, $1.7 \mathrm{M}$ ammonium sulphate $\mathrm{pH} 5.0$; (B) $0 \cdot 1 \mathrm{M}$ sodium citrate $\mathrm{pH} 5 \cdot 0$. Dried samples of lyophilised juice were dissolved in $2 \mathrm{ml}$ of buffer A. After centrifugation at $4000 \mathrm{rpm}$ for 10 minutes, to remove any debris, the sample was loaded onto a $7 \cdot 5 \times 75$ mm TSK phenyl-5PW column (Beckman) equilibrated in buffer A. Proteins were eluted by increasing buffer $\mathrm{B}$ ratio from $0 \%$ to $100 \%$ in 30 minutes. S2-5 isoforms of lithostathine were eluted as a single peak at $19 \cdot 2$ minutes and analysed on SDS PAGE with corresponding immunological characterisation by western blotting with a specific lithostathine polyclonal antibody. ${ }^{12}$ Protein concentrations were determined by integration of the peaks. Protein concentration (in $\mathrm{mg} / \mathrm{ml}$ ) was determined by integration of the optical density at $280 \mathrm{~nm}$; the extinction coefficients used were equal to $2 \cdot 8$ for lithostathine, which contains a high proportion of tyrosine residues, ${ }^{4}$ and 1.9 for the other pancreatic proteins. As protein concentration in the pancreatic juice is highly variable depending upon the physiological conditions, we considered the lithosthatine/total protein ratio. We checked that in the same patient, this ratio was unchanged in the various sampling conditions (basal, secretin or caerulein stimulated secretion). However, we also estimated actual concentration $(\mu \mathrm{g} / \mathrm{ml})$.

\section{PATIENTS}

Pancreatic juice samples were collected from 41 patients divided into five groups. Group 1: patients suffering from alcoholic chronic calcifying pancreatitis (ACCP) with or without visible calcification on plain films of the abdomen $(n=10 \mathrm{men})$. The diagnosis of CCP was based on clinical, aetiological, and morphological data (endoscopic retrograde cholangiopancreatography findings), according to the 2nd Marseille Symposium on classification of pancreatitis ${ }^{13}$. Group 2: patients suffering from non-alcoholic chronic calcifying pancreatitis (NACCP); this group included three men and two women with idiopathic chronic pancreatitis and one man with a hereditary form of the disease. Two patients presenting with pancreatic protein lithiasis ${ }^{14}$ were excluded. Group 3: alcoholic patients without chronic pancreatitis (eight men). Subjects were classified as alcoholic if their daily alcohol consumption had been above 75 $\mathrm{g}$ of pure alcohol for at least three years. Group 4: patients with pancreatic disorders excluding CCP (four men and four women), namely biliary acute pancreatitis $(n=2)$, pancreas divisum $(n=3)$, pancreatic adenocarcinoma $(n=1)$, and mucinous ductal ectasia $(n=2)$. Group 5: non-alcoholic patients without pancreatic disease (nine men).

\section{STATISTICAL ANALYSIS}

The five groups of patients were simultaneously compared by the Bonferroni $t$ test. $^{15}$ Differences with $p$ values of $<0.05$ were considered statistically significant.

\section{Results}

IMMUNOREACTIVITY OF THE ISOFORMS OF LITHOSTATHINE IN THE MONOCLONAI POLYCLONAL (SANDWICH) ELISA

The lithostathine fraction of a pancreatic juice was immunopurified as already described. It contained mostly the S2-5 forms and also a small amount of the $\mathrm{S} 1$ form. Figure 1 shows 

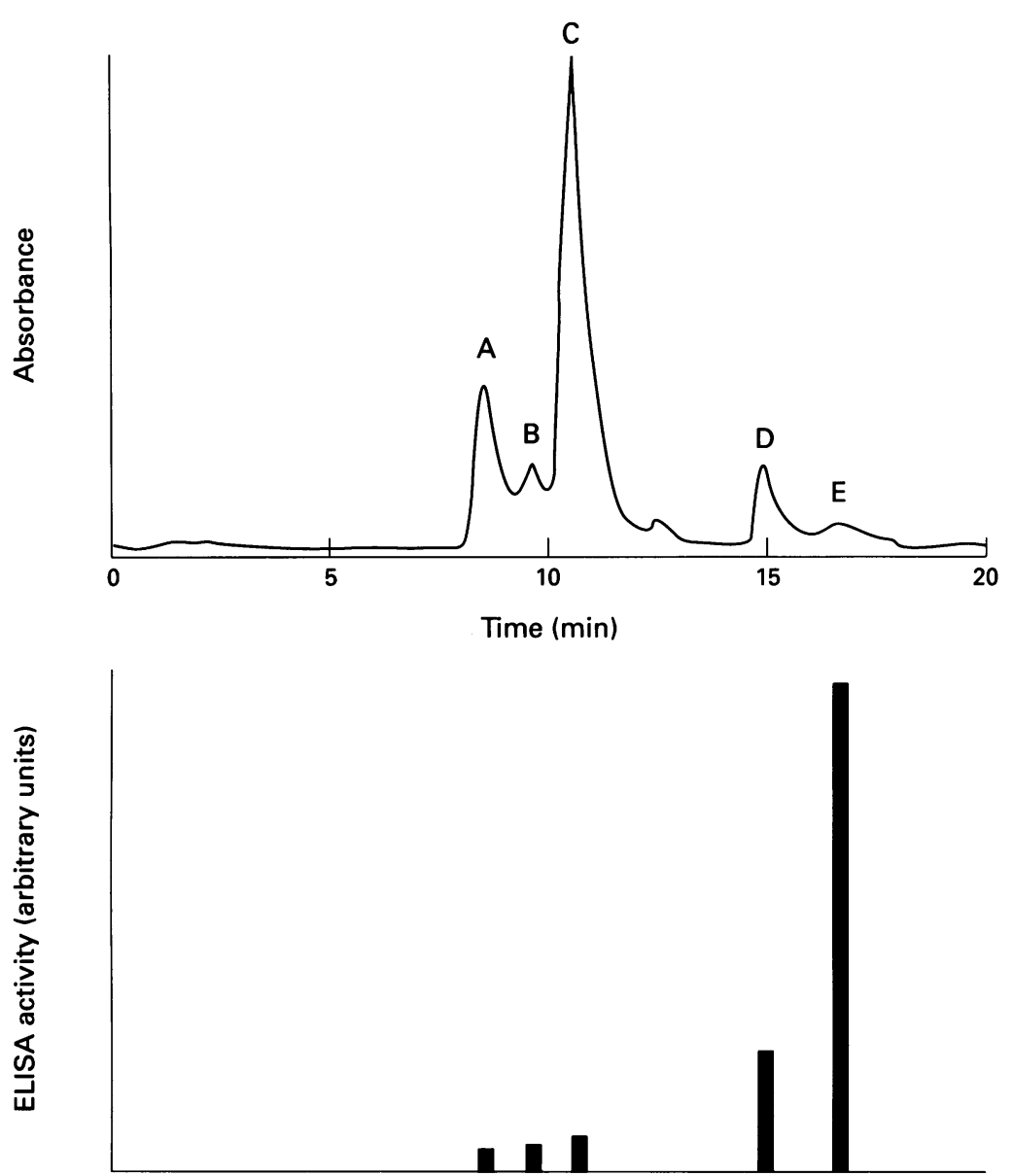

Figure 1: HPLC separation of lithostathine isoforms (top) and their comparative immunoreactivity in the ELISA test (bottom). Immunopurified lithostathine was further chromatographied on cation exchange HPLC. $A, B, C:$ secretory isoforms; D: hydrolysed lithostathine; $E$ : mixture of degraded products.

the elution profile of that lithostathine fraction, after resolution on HPLC. Lithostathine immunoreactivity in the ELISA was measured under each peak. In peaks $A, B$, and $C$, which contained mixtures of the S2 to S5 forms in variable proportion, the specific immunoreactivity (OD of the ELISA per $\mu \mathrm{g}$ protein) was very low compared with peaks $D$ and $E$, which showed very high specific immunoreactivities. Hence, generation of lithostathine $S 1$ as well as other hydrolysed forms, even in small amounts, will significantly change the reliability of the lithostathine ELISA assay.

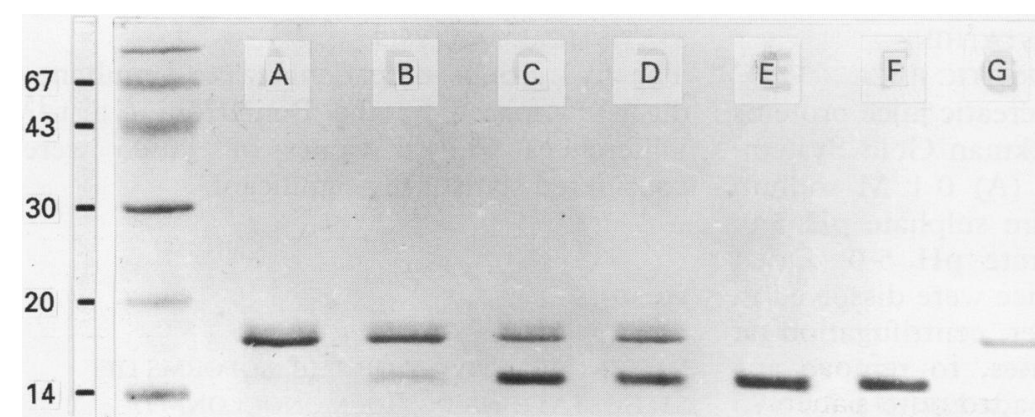

Figure 2: Susceptibility of lithostathine to trypsin action. Lithostathine $(29 \mu M)$ was incubated with a low concentration of trypsin (5.5 nM) and then analysed on SDS gel electrophoresis. Duration of the incubation with trypsin: 0.5 hours $(B), 1$ hour $(C), 2$ hours $(D), 8$ hours $(E)$, and 24 hours $(F)$; controls: before trypsin action $(A)$ and after 24 hours without trypsin $(G)$. Molecular weight $\left(\times 10^{-3}\right)$ as estimated from marker proteins (Pharmacia LKB, Sweden) are shown on the left.
GENERATION OF LITHOSTATHINE S1 BY TRYPSIN HYDROLYSIS OF LITHOSTATHINE S2-5 As already stated, all samples of pancreatic juice were routinely checked after collection for absence of uncontrolled trypsinogen activation. This was done by controlling the absence of detectable chymotrypsin activity because chymotrypsinogen is, among pancreatic zymogens, one of the most susceptible to activation by trypsin. Yet lithostathine $S 1$ was often present in samples devoid of detectable chymotrypsin activity, suggesting that the affinity of trypsin for lithostathine is much higher than for chymotrypsinogen, and that smaller amounts of trypsin are sufficient for lithostathine S2-5 cleavage. This is why we monitored lithostathine transformation by minimal amounts of trypsin. Trypsinogen concentration in juice is about $300 \mu \mathrm{g} / \mathrm{ml}$. We used $0 \cdot 13,0 \cdot 04$, and $0.013 \mu \mathrm{g} / \mathrm{ml}$, corresponding respectively to $0.04,0.01$, and $0.004 \%$ of total potential trypsin activity in juice. With $0.13 \mu \mathrm{g} / \mathrm{ml}$ trypsin, lithostathine was already completely transformed after a two hour incubation. With $0.013 \mu \mathrm{g} / \mathrm{ml}, 25 \%$ of the lithostathine was transformed after 24 hours. It is noteworthy that under these experimental conditions, only lithostathine S1 was generated, showing that among possible trypsin cleavage sites in the molecule, the Arg11-Ile12 bond is by far the most sensitive (Fig 2).

\section{HPLC SEPARATION OF LITHOSTATHINE FROM} OTHER PANCREATIC PROTEINS

Experimental conditions were defined to permit separation of lithostathine from other proteins of pancreatic juice after fractionation on HPLC. To take advantage of the comparatively high polarity of lithostathine, compared with other pancreatic proteins, chromatographic separation was based on hydrophobic interactions at $\mathrm{pH} 5 \cdot 0$, using a phenyl-TSK column. In these conditions the elution profile of total pancreatic proteins showed several peaks (Fig 3A). SDS PAGE with corresponding western blot analysis showed that all soluble S2-5 isoforms of lithostathine were eluted as a single peak at $19 \cdot 2$ minutes, no other protein contaminant being detectable on the gels (Fig 4). When purified lithostathine S2-5 and its hydrolysed form S1 were submitted to the same HPLC conditions, the elution profile showed two peaks: lithostathine S2-5 migrated at $19 \cdot 2$ minutes and lithostathine $\mathrm{S} 1$ at $17 \cdot 8$ minutes (Fig $3 \mathrm{C}$ ). In contrast, absence of significant amounts of other proteins under the lithostathine peak was checked as follows: a sample of juice was loaded onto the immunoaffinity column used for lithostathine purification. The flow through of the column on which lithostathine had been retained was analysed on the Phenyl-TSK column. All peaks were conserved apart from the lithostathine peak, which had disappeared (Fig 3B).

LITHOSTATHINE QUANTIFICATION AFTER HPLC FRACTIONATION OF PANCREATIC JUICE PROTEINS Quantification was standardised by running a 

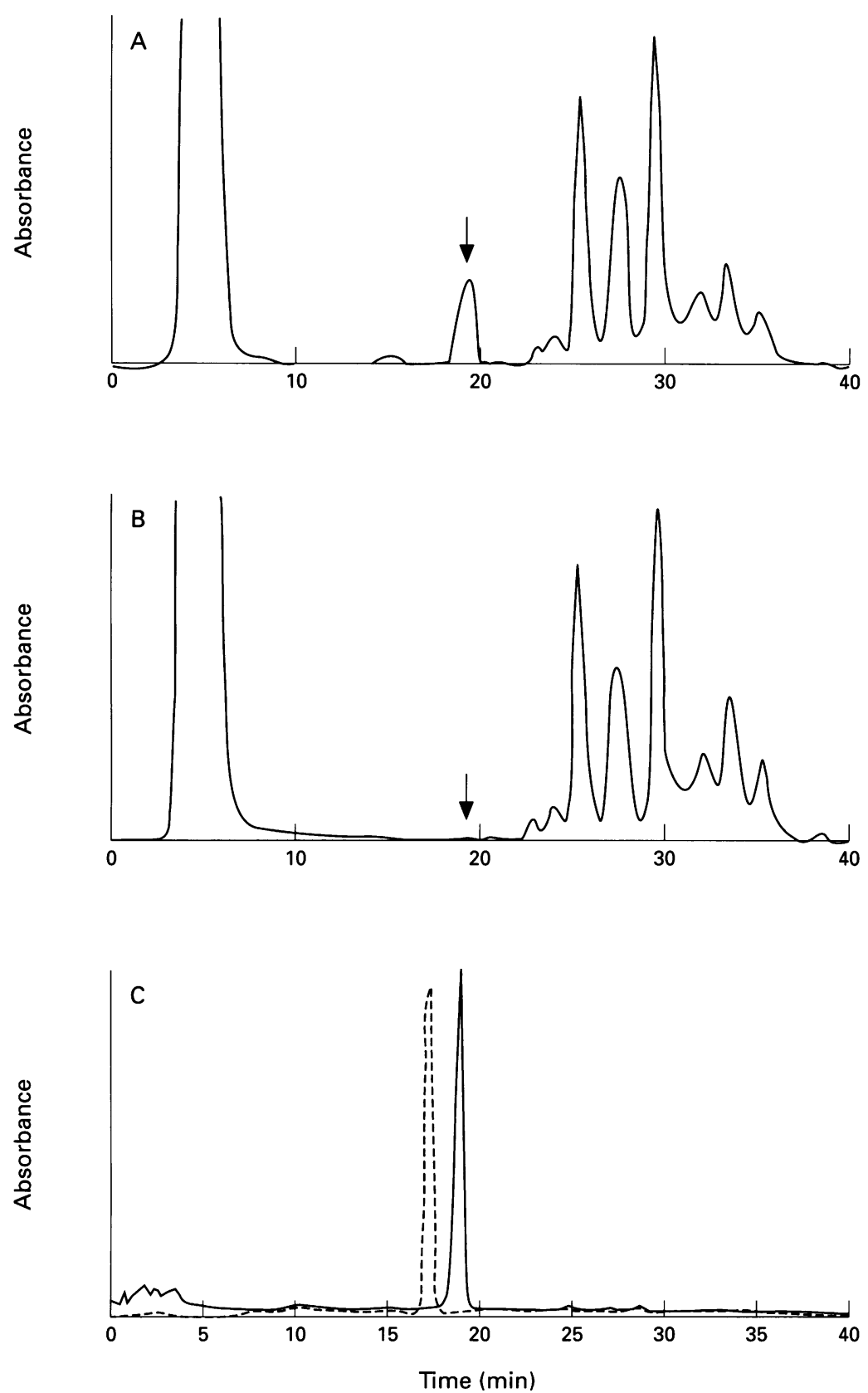

Figure 3: HPLC separation of pancreatic juice proteins. HPLC profiles obtained before $(A)$ and after $(B)$ immunoadsorption of lithostathine. The arrows show the peak removed by the specific binding with the anti-lithostathine antibody. This peak was eluted at the same time as purified lithostathine $S 2-5$. (C) solid line, S2-5 isoforms; broken line, $S 1$ isoform.) from the five groups of patients. Peaks corresponding to secretory proteins, including lithostathine appear at the same times but their comparative areas vary widely. Figures 6 and 7 show the amounts of lithostathine, estimated as already described. The nine non-alcoholic patients without pancreatic disease (control group) had a lithostathine concentration mean (SD) of $16 \cdot 7(4 \cdot 3) \mu \mathrm{g} / \mathrm{mg}$ of total proteins. Similar values were obtained in patients with pancreatic diseases other than CCP $(20.5$ $(7 \cdot 5))$. By contrast, alcoholic CCP, nonalcoholic CCP, and alcoholic patients showed significantly lower values $(6 \cdot 7$ (3.9), $7 \cdot 2(3 \cdot 7)$, and $6.6(3.3) \mu \mathrm{g} / \mathrm{mg}$ of total proteins respectively; $\mathrm{p}<0 \cdot 001)$. When lithostathine concentrations were estimated in $\mu \mathrm{g} / \mathrm{ml}$ similar results were obtained: lithostathine concentrations in alcoholic CCP $(10.7(2 \cdot 8))$, non-alcoholic CCP $(10 \cdot 5(3 \cdot 1))$, and alcoholic patients $(18 \cdot 2$ $(10 \cdot 1))$ were significantly lower than in patients with other pancreatic diseases (35 (9)) and controls (40 (23)), $\mathrm{p}<0.001$.

\section{Discussion}

Lithostathine is present in the pancreatic secretion of all mammals tested so far. ${ }^{16}$ It is usually abundant, compared with other secretory non-enzymatic proteins. Studies in vitro have shown that lithostathine could inhibit the nucleation and growth of $\mathrm{CaCO} 3$ crystals. Because pancreatic juice is supersaturated in $\mathrm{CaCO} 3$, a mechanism controlling the spontaneous formation and growth of $\mathrm{CaCO} 3$ crystals is required to prevent duct obstruction. Lithostathine might be one of the elements of that mechanism, as already shown for proteins with similar structure and properties described in saliva ${ }^{1718}$ and urine. ${ }^{19}$ If lithostathine is a key factor in the prevention of stone formation, any change in its activity in juice will increase the risk of developing calcified calculi. Hence patients presenting with CCP would probably have diminished lithostathine activity in juice.

A study was conducted to compare the pancreatic concentration of lithostathine mRNA in patients with CCP and controls. ${ }^{7}$ That concentration was on average three times lower in patients, suggesting a significant decrease in lithostathine gene expression. Such a decrease predicts a diminished concentration of the protein in juice. Yet comparison of lithostathine concentration in the juice of patients and controls yielded conflicting results, although immunoassays were conducted with the same monoclonal antibody in all studies. A possible

Reliability of lithostathine quantification

\begin{tabular}{lll}
\hline & \multicolumn{2}{l}{ Lithostathine $(\mu g)$} \\
\cline { 2 - 3 } Added & Measured & Yield (\%) \\
\hline 0 & $10 \cdot 2$ & 0 \\
$12 \cdot 5$ & $21 \cdot 6$ & 91 \\
$25 \cdot 0$ & $34 \cdot 5$ & 97 \\
$50 \cdot 0$ & $53 \cdot 7$ & 87 \\
\hline
\end{tabular}

Increasing amounts of purified lithostathine were added to identical aliquots of a pancreatic juice sample. Recovery of the added lithostathine was monitored. The sample of pancreatic juice used in this experiment contained $10.2 \mu \mathrm{g} / \mathrm{ml}$ of
Mean (SD) values $(\mathrm{mg} / \mathrm{ml})$ of total protein concentrations were estimated for the pancreatic juice samples of the five groups of patients: alcoholic CCP $(1 \cdot 8(0 \cdot 5))$, non-alcoholic CCP $(1.9(0.9))$ alcoholic patients $(2.9(1.2))$, pancreatic diseases other than CCP $(2.5$ $(0 \cdot 8))$, controls $(2 \cdot 8(1 \cdot 4))$. Figure 5 gives examples of chromatographic patterns of juices 




Figure 4: SDS PAGE and western blot analysis of lithostathine purified by phenyl-TSK HPLC analysis. Western blot analysis with polyclonal lithostathine antibody (A) and SDS PAGE (B) of the protein eluted at $19 \cdot 2$ minutes (molecular weight $\times 10^{-3}$ ).

explanation for these discrepancies might be found in the peculiar structural features of the lithostathine molecule. Lithostathine appears in pancreatic juice under several forms; one of them (lithostathine $\mathrm{S} 1$ ) results from proteolytic cleavage of the polypeptide backbone. Lithostathine S1, independently described as PTP, forms thread like polymers at neutral $\mathrm{pH}$, which eventually sediment. ${ }^{2021}$ This is expected to modify some epitopes and generate new ones, which suggests that the native and hydrolysed forms of lithostathine might not be immunologically identical. As we showed, the hydrolysed form of lithostathine is much more reactive in the sandwich ELISA than the native forms. This might be because the commercial $\mathrm{mAB}$ used for captation in the test was initially selected with lithostathine extracted from stones, ${ }^{22}$ which has since been shown to be mostly hydrolysed.

Another matter of concern for the assay is the formation of fibrils during lithostathine transformation. Those fibrils have limited solubility ${ }^{20}$ and their concentration in a given aliquot of juice might not be representative of the amount of lithostathine in secretion. This might be an important difficulty for assays in juice samples, in which a lithostathine transformation is difficult to control. Small amounts of lithostathine $\mathrm{S} 1$ are often found in samples collected over a cocktail of protein inhibitors, and otherwise showing no evidence of activation. This was further supported by results in Fig 2 showing the extreme sensitivity of lithostathine to trypsin cleavage.

These findings show that lithostathine quantification in juice requires exceptional care. This could not be anticipated when studies comparing lithostathine concentrations in patients with CCP and healthy subjects were conducted and the results published at that time need to be controlled. Because immunological methods using the antibodies presently available cannot be relied upon, we developed a procedure for lithostathine quantification based on HPLC separation of all forms of the protein from other secretory proteins and direct estimation of the concentration by absorption at $280 \mathrm{~nm}$. In addition, samples selected for absence of activation by chymotrypsin assay were further controlled by analysis of their pattern on HPLC. The amounts of lithostathine measured in juice samples were used to compare lithostathine concentrations among groups of patients. A first comparison was made after calculating the mass ratio of lithostathine to total secretory protein, expressed as $\mu \mathrm{g}$ lithostathine per $\mathrm{mg}$ total protein (Fig 6). We have previously shown ${ }^{23}$ that ratio remains constant in a given patient when protein concentration changes during pancreatic secretory stimulation. In fact, such determination reflects the rate of lithostathine synthesis, compared with pancreatic secretory protein. Present results showed that the lithostathine to protein ratio was three times
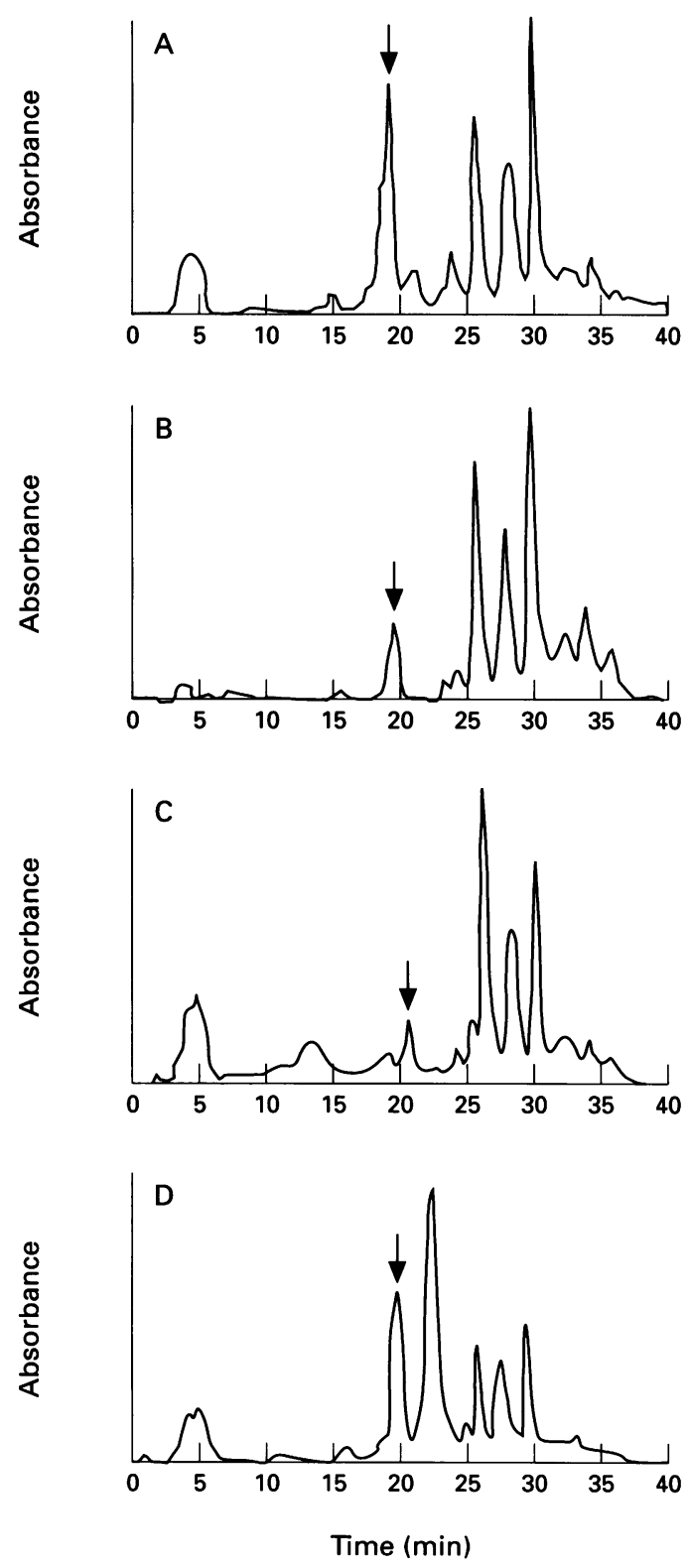

Figure 5: Typical HPLC patterns of pancreatic juice from the four groups of patients studied. (A) non-alcoholic patients without pancreatic disease; $(B) C C P$; $(C)$ alcoholic patients; (D) patients with pancreatic disorders excluding CCP. 


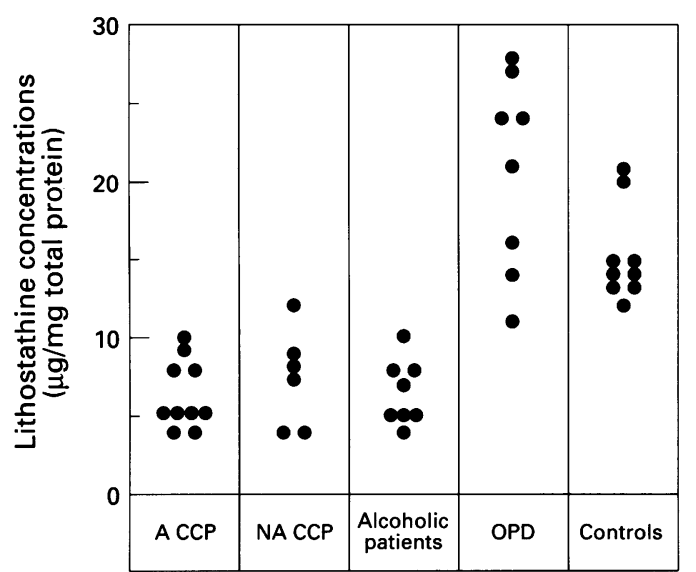

Figure 6: Lithostathine concentrations ( $\mu$ g per $m g$ total protein) in pancreatic juice from five groups of patients. Mean (SD) values were: alcoholic $\operatorname{CCP}(n=10): 6 \cdot 3$ $(2 \cdot 7)$; non-alcoholic CCP $(n=6): 7 \cdot 2(3 \cdot 7)$; alcoholic patients $(n=8): 6 \cdot 6(3 \cdot 3)$; other pancreatic diseases (OPD) $(n=8): 20 \cdot 5(7 \cdot 5)$; controls $(n=9): 16 \cdot 7(4 \cdot 3)$. Values for ACCP, NACCP, and alcoholic patients were significantly different from OPD and controls. $(p<0.001$.

lower in patients with CCP than in controls. ${ }^{7}$ Hence, CCP is associated with a decreased synthesis of lithostathine, compared with other secretory proteins.

The group of patients with chronic alcoholism and no pancreatic disease, however, showed the same decrease in relative synthesis of lithostathine as patients with CCP, suggesting that, in patients, low lithostathine synthesis might be associated with alcoholism and not with the disease in itself. To clarify that point we identified among CCP patients a group of six cases with causes other than alcoholism and saw that their comparative rate of lithostathine synthesis was also lowered, similar to patients with chronic alcoholic pancreatitis. It was concluded that decreased lithostathine synthesis is associated with CCP, whatever the aetiology, and that such a decrease is not sufficient to evoke the disease, as decreased lithostathine is found in chronic alcoholic patients without pancreatic disease.



Figure 7: Lithostathine concentrations $(\mu \mathrm{g} / \mathrm{ml})$ in pancreatic juice from five groups of patients. Mean (SD) values were: alcoholic $C C P(n=10): 10 \cdot 7(2 \cdot 8)$; nonalcoholic $C C P(n=6): 10 \cdot 5(3 \cdot 1)$; alcoholic patients $(n=8): 18 \cdot 2(10 \cdot 1)$; other pancreatic diseases $(n=8): 35$ (9); controls $(n=9): 40$ (23). Values for ACPC, NACCP, alcoholic patients were significantly different from other pancreatic diseases and controls. $(p<0.001$.
Lithostathine amounts in juice could also be used to calculate actual concentrations of the protein $(\mu \mathrm{g} / \mathrm{ml}$, Fig 7$)$. Those values reflect the inhibitory activity of the protein in juice. As such, they are of interest to investigate a possible relation between decreased lithostathine activity and occurrence of the disease. As Fig 7 shows, lithostathine concentration was decreased in all patients with CCP. Concentration was also decreased in alcoholic patients without pancreatic disease. Results in that group and in CCP patients were not statistically different, but suggested that lithostathine concentrations might be lower in CCP patients. We therefore conclude that lithostathine activity in juice is lower in CCP patients than in controls and that decrease is not sufficient to account for the disorder as alcoholic patients without pancreatic disease also show decreased lithostathine concentration.

Expressing lithostathine as relative amounts to total protein or as concentration led to similar conclusions. It should be borne in mind, however, that the volumes of juice samples collected by ERCP, which are used to calculate lithostathine concentrations, vary considerably during exogenous stimulation. In our protocol, sample collection was standardised to reduce to a minimum the dispersion of the results. Such standardisation might be difficult to achieve in general practice. When lithostathine quantification is requested in a patient under investigation for CCP, it is therefore advisable to calculate the comparative amount of lithostathine to total secretory protein (as in Fig 6), which is independent of the sample collected and provides the same information as the actual concentration.

HPLC quantification of lithostathine in pancreatic juice is reliable but time consuming compared with an immunoassay. It is well adapted to experimental studies but efforts should be made to make available a reliable assay, simple and cheap enough for routine clinical use.

Part of this paper has been published in abstract form at the AGA meeting in Boston, May 1993.

1 Sarles H, Dagorn J-C, Giorgi D, Bernard J-P. Renaming pancreatic stone protein as lithostathine. Gastroenterology 1990; 99: 900-1

2 De Caro A, Lohse J, Sarles H. Characterization of a protein isolated from pancreatic calculi of men suffering from chronic calcifying pancreatitis. Biochem Biophys Res Commun 1979; 87: 1176-82.

3 De Caro A, Multigner L, Lafont H, Lombardo D, Sarles H. The molecular characteristics of a human acidic phosphoprotein that inhibits calcium carbonate crystal growth. Biochem $\mathcal{f}$ 1984; 222: 669-77.

4 De Caro A, Bonicel J, Rouimi P, De Caro J, Sarles H, Rovery $M$. Complete aminoacid sequence of an immunoreactive form of human pancreatic stone protein isolated from pancreatic juice. Eur $\mathcal{F}$ Biochem 1987; 168: isolated from pancreatic juice. Eur f Biochem 1987; 168: 201-7.

5 De Caro A, Adrich Z, Fournet B, Capon C, Bonicel J, De Caro J, et al. N-terminal sequence extention in the glycosylated forms of human pancreatic stone protein. The 5oxoproline N-terminal chain is O-glycosylated on the 5th aminoacid residue. Biochim Biophys Acta 1989; 994: 281-4.

6 Bernard J-P, Adrich Z, Montalto G, De Caro A, De Reggi $\mathrm{M}$, Sarles $\mathrm{H}$, et al. Inhibition of nucleation and crystal growth of calcium carbonate by human lithostathine. Gastroenterology 1992; 103: 1277-84.

7 Giorgi D, Bernard J-P, Rouquier S, Iovanna J, Sarles H, Dagorn J-C. Secretory pancreatic stone protein messenger RNA. Nucleotide sequence and expression in chronic calcifying pancreatitis. $\mathcal{f}$ Clin Invest 1989; 84: 100-6. 
8 Provansal-Cheylan M, Mariani A, Bernard J-P, Sarles H, Dupuy P. Pancreatic stone protein: quantification in pancreatic juice by ELISA and comparison with other creatic juice by ELISA and com
methods. Pancreas $1989 ; 4: 680-9$.

9 Schmiegel WH, Burchert M, Kalthoff $H$, Roeder C, Butzow $\mathrm{C}$, Grimm $\mathrm{H}$, et al. Immunological characterization and quantitative distribution of pancreatic stone protein in sera and pancreatic secretions in pancreatic disorders. Gastroenterology 1990; 99: 1421-30.

10 Montalto G, Lusher M, De Caro A, Multigner L, Sarles H Delaage $M$. Analyse au moyen d'un anticorps monoclona des composants du suc pancreatique humain apparentés la proteine des calculs pancreátiques. $C R$ Acad $S c i$ Paris 1985; 300: 199-202.

11 Laemmli UK. Cleavage of structural proteins during the assembly of the head of bacteriophage T4. Nature 1970; 227: $680-5$

12 Burnette WN. Western blotting: electrophoretic transfer of proteins from sodium dodecyl sulfate polyacrylamide gels to unmodified nitrocellulose and radiographic detection with antibody and radioiodinated protein A. Anal Biochem 1981; 112: 195-203.

13 Sarles H. Definition and classifications of chronic pancreatitis. Pancreas 1991; 6: 470-4.

14 Sarles H, Camarena J, Gomez-Santana C. Radiolucent and calcified pancreatic lithiasis: two different diseases. Role of alcohol and heredity. Scand 7 Gastroenterol 1992; 27: 71-6.

15 SAS Institute inc. SAS/STAT User's guide, release 6.06 edition. Cary, CN: 1988.

16 Bernard J-P, Adrich Z, Montalto G, Multigner L, Dagorn J$\mathrm{C}$, Sarles H, et al. Immunoreactive forms of pancreatic stone protein in six mammalian species. Pancreas 1991; 6: 62-7.

17 Schlesinger DH, Hay DI. Complete covalent structure of statherin, a tyrosin rich acidic peptide which inhibits calcium phosphate precipitation from human parotid saliva. Biol Chem 1977; 252: 1689-95.

18 Hay DI, Moreno EC, Schlesinger DH. Phosphoprotein inhibitors of calcium phosphate precipitation from salivary secretions. Inorganic Perspectives in Biological Medicine 1979; 2: 271-85.

19 Nakagawa Y, Kaiser ET, Coe FL. Isolation and characterisation of calcium oxalate crystal growth inhibitors from human urine. Biochem Biophys Res Commun 1978; 84: 1038-44.

20 Gross J, Brauer AW, Bringhurst RF, Corbett C, Margolies MN. An unusual bovine pancreatic protein exhibiting pH-dependent globule fibril transformation and unique pH-dependent globule fibril transformation and unique aminoacid

21 Gross J, Carlson RI, Brauer AW, Margolies MN, Warshaw $\mathrm{AL}, \mathrm{Wands} \mathrm{JR}$. Isolation, characterisation and distribution of an unusual pancreatic human secretory protein. $f$ Clin Invest 1995; 76: 2115-26.

22 Provansal-Cheylan $M$, Lusher M, De Caro A, Multigner L Montalto $\mathrm{G}$, Sarles $\mathrm{H}$, et al. Monoclonal antibodies to prosen and 1986; 68: 1109-13 1986; 68: $1109-13$.

Multigner L, Sarles H, Lombardo D, De Caro A Pancreatic stone protein II implication in stone formation during the course of chronic calcifying pancreatitis. Gastroenterology 1985; 89: 387-91. 